\title{
Antitumor activity of AZ64 via G2/M arrest in non-small cell lung cancer
}

\author{
YUWEN XUE ${ }^{1,3}$, HENING REN $^{4}$, WEI XIAO ${ }^{1}$, ZUOMING CHU $^{3}$, J. JACK LEE ${ }^{2}$ and LI MAO $^{4}$ \\ ${ }^{1}$ Department of Respiratory Medicine, Qilu Hospital of Shandong University, Jinan, Shandong 250012, P.R. China; \\ ${ }^{2}$ Department of Biostatistics, and ${ }^{3}$ Thoracic Head \& Neck Medical Oncology, The University of Texas \\ MD Anderson Cancer Center, Houston, TX 77030; ${ }^{4}$ Department of Oncology and Diagnostic \\ Sciences, University of Maryland Dental School, Baltimore, MD 21201, USA
}

Received June 22, 2012; Accepted August 6, 2012

DOI: $10.3892 /$ ijo.2012.1619

\begin{abstract}
AZ64 is a novel antitumor agent designed as a tropomyosin-related kinase (Trk) inhibitor; however, its effect on lung cancer and its mechanism of action remain unclear. This study aimed to elucidate the antitumor activity of AZ64 and its mechanism of action against non-small cell lung cancer (NSCLC). Our results demonstrate that AZ64 has a potent anti-proliferative effect on NSCLC cells and acts in a doseand time-dependent manner. We also demonstrate that AZ64 suppresses the anchorage-independent growth and invasion of NSCLC cells. In vivo experiments demonstrated that AZ64 significantly reduced the tumor growth of NSCLC xenografts in nude mice and was well-tolerated. Mechanistic experiments revealed that AZ64 induced the G2/M arrest of NSCLC cells by the accumulation of phospho-Cdc2 (Tyr15) at the G2/M transition, following the downregulation of Cdc25C expression. Collectively, our data demonstrate that AZ64 is a potential antitumor drug that may be used for the treatment of NSCLC, which functions by targeting the G2/M transition via the inhibition of the dephosphorylation of phospho-Cdc2 (Tyr15).
\end{abstract}

\section{Introduction}

Lung cancer is one of the most frequent type of cancer and the leading cause of cancer-related mortality in the Unites States and developed countries. In the United States, 226,160 new cases of lung cancer and 160,340 deaths from lung cancer are estimated to occur in 2012 (1). Despite efforts to improve

Correspondence to: Dr J. Jack Lee, Department of Biostatistics, The University of Texas MD Anderson Cancer Center, Houston, TX 77030, USA

E-mail: jjlee@mdanderson.org

Dr Li Mao, Department of Oncology and Diagnostic Sciences, University of Maryland Dental School, Baltimore, MD 21201, USA

E-mail:1mao@umaryland.edu

Key words: AZ64, non-small cell lung cancer, G2/M arrest, phospho$\mathrm{Cdc} 2$ (Tyr15), Cdc25C early diagnosis and treatment, the survival rates of the patients with lung cancer have not significantly improved over the past 30 years. The overall five-year survival of lung cancer only increased from $13 \%$ between 1987 to 1989 , to $16 \%$ between 2001 to 2007 in the US $(1,2)$. The majority $(80 \%)$ of lung cancer cases are non-small cell lung cancer (NSCLC) (3). Therefore, the development of novel antitumor drugs for the treatment of NSCLC is imperative in order to improve the efficacy of lung cancer therapy and prognosis.

One of the most effective antitumor mechanisms is the inhibition of uncontrolled cell growth. The G2/M transition is a crucial step in the cell cycle for controlling cell proliferation. The agents targeting G2/M phase have been used in combination with chemotherapy and sensitization to radiotherapy. However, compared with agents targeting the G1 and S phase, only a few antitumor agents affecting the G2/M phase have been approved. Vinca alkaloids and taxanes are the only antitumor drugs affecting the G2/M phase which have been used in clinical practice for the treatment of NSCLC. Recently, certain novel anti-NSCLC agents have been reported to have an inhibitory effect by arresting cells in the $\mathrm{G} 2 / \mathrm{M}$ phase. However, their clinical efficacy and molecular mechanisms involved are not yet well understood (4-6).

AZ64 (AstraZeneca Pharmaceuticals) is a novel anticancer agent designed to target tropomyosin-related kinase (Trk)A, $\mathrm{B}$ and $\mathrm{C}$. However, its role and mechanisms in the treatment of NSCLC remain unclear. In this study, we investigated its antitumor activity against NSCLC, as well as its mechanism of action.

\section{Materials and methods}

Cell lines and reagents. Six human lung cancer cell lines including three adenocarcinoma cell lines (A549, HCC827 and H1944), two large cell carcinoma cell lines (H460 and H1299) and one squamous carcinoma cell line (Calu-1) were used in this study. All the cell lines were purchased from the American Type Culture Collection and were cultured in Dulbecco's modified Eagle's medium (DMEM) supplemented with $5 \%$ fetal bovine serum (FBS), $1 \%$ penicillin-streptomycin and $1 \%$ glutamine. The cells were grown in a $37^{\circ} \mathrm{C}$ incubator in a humidified atmosphere of $5 \% \mathrm{CO}_{2}$. AZ64 compound was 
synthesized and supplied by AstraZeneca Pharmaceuticals. It was dissolved in dimethylsulfoxide (DMSO) with a stock concentration of $10 \mathrm{mM}$ and stored at $-20^{\circ} \mathrm{C}$ under lightprotected conditions. The final concentrations of DMSO in the experiment did not exceed $0.1 \%$. The antibodies against cyclin B, Cdc2, phospho-Cdc2, Cdc25C, Polo-like kinase 1 (Plk1) and Aurora-A were purchased from Cell Signaling Technology. $\beta$-tubulin antibody was purchased from Santa Cruz Biotechnology Inc. 3-(4,5-dimethylthiazol-2-yl)-2,5-diphenyltetrazoliumtromide (MTT) reagent was purchased from Sigma-Aldrich Corp. The BD Matrigel invasion assay kit was purchased from BD Biosciences. The BCA Protein Assay kit was purchased from Thermo Scientific Pierce Co. The Vectastain Elite ABC kit was purchased from Vector Laboratories.

Cell culture and cell proliferation assay (MTT assay). A549, HCC827, H1944, H460, H1299 and Calu-1 cells were plated into 96 -well plates at a density of $5 \times 10^{3}$ cells/well and incubated at $37^{\circ} \mathrm{C}$ with $5 \% \mathrm{CO}_{2}$ for $24 \mathrm{~h}$. Subsequently, 0 (0.1\% DMSO), $0.25,0.5,1.0,2.0,4.0$ and $8.0 \mu \mathrm{M}$ concentrations of AZ64 were added to the culture medium. After $72 \mathrm{~h}$ of exposure to AZ64, cell proliferation was evaluated by the MTT assay. Briefly, the medium was removed and replaced by $200 \mu \mathrm{l}$ fresh medium with $500 \mu \mathrm{g} / \mathrm{ml}$ MTT per well. The cells were incubated for $4 \mathrm{~h}$. The medium was then removed and $200 \mu \mathrm{l}$ of DMSO were added to each well. The absorbance value of each well was determined spectrophotometrically at $570 \mathrm{~nm}$ on a Microplate ELISA Reader (Bio-Tek Instruments). The experiment was performed in triplicate. Each experiment was repeated three times.

Real-time cell growth observation by the real-time cell electronic sensing (RT-CES) system. ACEA RT-CES, (ACEA Biosciences Inc.), a microelectronic cell sensor system, was used to measure the cell index continuously and quantitatively. A549 cells were seeded in $16 \times$ E-plates at a density of $5 \times 10^{3}$ cells/well and incubated in a $37^{\circ} \mathrm{C}$ incubator with $5 \% \mathrm{CO}_{2}$. The cell index was measured every $30 \mathrm{~min}$ by RT-CES. After $24 \mathrm{~h}$ of incubation, 2.5 and $5.0 \mu \mathrm{M}$ of AZ64 and 0.1\% DMSO (control) were added to the medium, and the cell growth was then monitored every $30 \mathrm{~min}$ for another $72 \mathrm{~h}$ by RT-CES. The experiment was performed in triplicate for each treatment condition and was repeated three times.

Anchorage-independent colony formation assay. Six-well plates were pre-coated with $2 \mathrm{ml}$ of bottom agar of $0.6 \%$ lowmelting agarose with DMEM. Subsequently, $2 \mathrm{ml}$ of top agar consisting of $0.3 \%$ low-melting agarose, DMEM, $5 \times 10^{3}$ cells and $2.5 \mu \mathrm{M}$ AZ64 or $0.025 \%$ DMSO were added to each well. After solidification, each well was covered with $1 \mathrm{ml}$ of DMEM with $2.5 \mu \mathrm{M}$ AZ64 or $0.025 \%$ DMSO and incubated in a $37^{\circ} \mathrm{C}$, $5 \% \mathrm{CO}_{2}$ incubator. The covering medium was refreshed every three days. After two weeks, the colonies of $>100 \mu \mathrm{m}$ were counted under a microscope at $\mathrm{x} 4$ magnification. The experiment was performed in triplicate for each treatment condition and was repeated three times.

In vitro cell invasion assay. The invasive ability of A549 cell was assayed using BD BioCoat Matrigel invasion chambers
(Becton-Dickinson, San Jose, CA). Briefly, the chambers were rehydrated with serum-free medium supplemented with $2.5 \mu \mathrm{M}$ AZ64 or $0.025 \%$ DMSO. The A549 cells were then seeded in the upper chamber at a density of $2.5 \times 10^{4}$ cells/well in serum-free medium supplemented with $2.5 \mu \mathrm{M} \mathrm{AZ64} \mathrm{or}$ $0.025 \%$ DMSO, whereas the lower chamber contained $10 \%$ FBS medium with $2.5 \mu \mathrm{M}$ AZ64 or $0.025 \%$ DMSO. After $20 \mathrm{~h}$ of incubation at $37^{\circ} \mathrm{C}$, the non-invasive cells on the upper surface of the chamber membranes were removed by a cotton-tipped swab. The invasive cells on the lower surface of the chamber membrane were stained with crystal violet and counted at randomly chosen fields under a light microscope at x10 magnification. The experiment was repeated three times.

Cell cycle analysis by flow cytometry (FCM). The cell cycle analysis was performed by FCM with DNA propidium iodide (PI) staining. The A549, HCC827, H1944 and Calu-1 cells were treated with $2.5 \mu \mathrm{M}$ AZ64 or $0.025 \%$ DMSO for $24 \mathrm{~h}$ and then harvested by trypsinization. The cells were fixed with $1 \mathrm{ml}$ of $70 \%$ cold ethanol overnight and then stained with staining buffer containing $0.01 \%$ PI, $0.1 \%$ sodium citrate, $0.3 \%$ Triton X-100 and $0.01 \%$ RNase A for $1 \mathrm{~h}$ in the dark. The DNA content and cell cycle distribution were determined using a BD FACSCalibur flow cytometer and CellQuest software (Becton-Dickinson). The experiments were repeated three times for the A549 cells and two times for the other cell lines. Furthermore, the A549 cells were treated with AZ64 at various concentrations of $0,0.5,1,2.5$ and $5 \mu \mathrm{M}$ for $24 \mathrm{~h}$ and then the cell cycles were analyzed by FCM as described above. The experiments were repeated two times.

Immunofluorescence assay of microtubule and DAPI staining of chromosome. The A549 cells were cultured on the coverslips and treated with $0.025 \%$ DMSO, $2.5 \mu \mathrm{M}$ AZ64 or $0.0625 \mu \mathrm{g} /$ $\mathrm{ml}(73 \mathrm{nM})$ of paclitaxel for $24 \mathrm{~h}$. The cells were fixed with $4 \%$ formaldehyde for $15 \mathrm{~min}$ and were then permeabilized with $0.5 \%$ Triton X-100 in PBS for 10 min. After blocking with 5\% BSA for $30 \mathrm{~min}$, the cells were incubated with anti- $\beta$-tubulin monoclonal antibody (1:100 in the blocking solution) for $2 \mathrm{~h}$ at $37^{\circ} \mathrm{C}$ followed by incubation with FITC-conjugated goat anti-mouse $\mathrm{IgG}$ and DAPI (1:2000) for $1 \mathrm{~h}$ at $37^{\circ} \mathrm{C}$. Images of the microtubules and chromosomes were obtained using a confocal fluorescence microscope. Mitotic index was calculated by the ratio of the number of cells in mitosis (including the cell with condensed chromosomes, aligned chromosomes and segregated chromosomes) to the total number of cells. The experiment was repeated three times.

Western blot analysis. The A549 cells were treated with $2.5 \mu \mathrm{M}$ of AZ64 for $0,2,4,6,8,12,16,24$ and $36 \mathrm{~h}$. The cells were harvested by scraping into lysis buffer and incubated on ice for $10 \mathrm{~min}$. Afterwards, the lysates were centrifuged at $14,000 \mathrm{rpm}$ for $20 \mathrm{~min}$ at $4^{\circ} \mathrm{C}$ and then the supernatants were collected into new tubes. The protein concentrations were determined using the Pierce BCA protein assay kit. Equal amounts of protein were then loaded onto a $10 \%$ SDS-PAGE gel. Electrophoresis was run at $150 \mathrm{~V}$ for $60-90 \mathrm{~min}$ and then the separated proteins were transferred onto a nitrocellulose membrane at $100 \mathrm{~V}$ for $60-90 \mathrm{~min}$. After blocking with $5 \%$ non-fat milk for $1 \mathrm{~h}$, the membrane was incubated with primary 
antibodies against Aurora-A, Plk1, Cdc25C, Cdc2, phospho$\mathrm{Cdc} 2$ (Tyr15), cyclin B and $\beta$-actin (as the control) overnight at $4^{\circ} \mathrm{C}$. The membrane was then incubated with HRP-conjugated secondary antibody $(1: 10,000)$ for $60 \mathrm{~min}$ at room temperature. The signal was detected using the enhanced chemiluminescence (NEN Life Science Products, Boston, MA) detection system. The experiment was repeated two times.

To further investigate the effect of AZ64 on G2/M checkpoint proteins in the cell cycle, A549 cells were synchronized to the $\mathrm{S}$ phase by $2.5 \mu \mathrm{M}$ thymidine treatment for $18 \mathrm{~h}$. Subsequently, $2.5 \mu \mathrm{M}$ AZ64 or $0.025 \%$ DMSO were added to the medium at the time of thymidine release. The cells were harvested at $0,3,5,6,7,8$ and $9 \mathrm{~h}$ after treatment. Western blot analysis was performed with $\mathrm{Cdc} 2$, phospho-Cdc2 (Tyr15) and $\beta$-actin antibodies. The cell cycle was examined by FCM assay. The experiment was repeated two times.

Immunocytochemistry (ICC) staining for phospho-Cdc2 (Tyr15). The A549 cells were cultured on the coverslips and were treated with $2.5 \mu \mathrm{M}$ AZ64 or $0.025 \%$ DMSO alone in triplicate. At $24 \mathrm{~h}$ after exposure, the cells were fixed with $4 \%$ formaldehyde for $15 \mathrm{~min}$ and permeabilized with $0.5 \%$ Triton X-100 for $10 \mathrm{~min}$ at room temperature. The ICC staining was performed using a Vectastain $\mathrm{ABC}$ kit according to the supplier's instructions. Briefly, the endogenous peroxidase was inactivated with $3 \% \mathrm{H}_{2} \mathrm{O}_{2}$ for $15 \mathrm{~min}$. Blocking was performed with avidin for $10 \mathrm{~min}$, biotin for $10 \mathrm{~min}$ and normal goat serum for $30 \mathrm{~min}$. Afterwards, the cells were incubated with 1:50 anti-phospho$\mathrm{Cdc} 2$ (Tyr15) antibody overnight at $4^{\circ} \mathrm{C}$, and then incubated with biotinylated secondary antibody solution for $30 \mathrm{~min}$ followed by incubation with ABC Reagent for $30 \mathrm{~min}$. After washing, the cells were incubated with 3,3'-diaminobenzidine (DAB) solution for $2 \mathrm{~min}$. The staining results were observed under a light microscope. The extent of phospho-Cdc2 (Tyr15) staining was calculated using the $\mathrm{H}$-score semi-quantitative method. Based on the staining intensity $(0$, negative; $1+$, weak; $2+$, moderate; and 3+, strong) and the percentages of the cells stained at each intensity level, the $\mathrm{H}$-score $=(\%$ at 0$) \times 0+(\%$ at $1+) \times 1+(\%$ at $2+) \times 2+(\%$ at $3+) \times 3$ was calculated.

Antitumor activity in vivo. To investigate the antitumor activity of AZ64 in vivo, a human tumor xenograft model was established. Athymic nude mice were obtained from the National Cancer Institute. Sixteen male athymic Swiss nude (nu/nu) mice aged 5-6 weeks with a weight of 20-22 g were used. All the experimental procedures and care for the mice were approved by the Institutional Animal Care and Use Committee and the Department of Veterinary Medicine of the MD Anderson Cancer Center. A total of $100 \mu \mathrm{l}$ of A549 cells $\left(2 \times 10^{6}\right)$ were injected subcutaneously (s.c.) into a single dorsal site of each mouse. When the tumors reached $60-110 \mathrm{~mm}^{3}$ in volume, the mice were randomly divided into the AZ64-treated group and the control group ( $\mathrm{n}=8$ per group). AZ64 dissolved in hydroxypropyl methylcellulose (HMPC) was administered by gavage to the mice in the AZ64-treated group $(100 \mathrm{mg} / \mathrm{kg}$ body weight) and the vehicle was administered to the control group. The tumor size and mouse weight were measured every four days for a total of 36 days. Tumor volume (TV) was calculated as TV $\left(\mathrm{mm}^{3}\right)=$ length $(\mathrm{L}) \mathrm{x}$ width $(\mathrm{W})^{2} / 2$. Tumor size was expressed by relative tumor volume $\left(\mathrm{RTV}_{\mathrm{n}}\right)=\mathrm{TV}_{\mathrm{n}} / \mathrm{TV}_{0}$.
Statistical analysis. The data are presented as the means \pm standard deviation (SD). The Student's t-test was used to analyze the statistical significance of the mean differences between two groups for normal distributed variables. Two-sided P-values $\leq 0.05$ were considered to indicate statistically significant differences.

\section{Results}

AZ64 inhibits proliferation of NSCLC cells in a dose- and time-dependent manner. To evaluate the effect of AZ64 on NSCLC cell growth, three adenocarcinoma cell lines (A549, HCC827 and H1944), two large cell carcinoma cell lines (H460 and H1299), and one squamous carcinoma cell line (Calu-1) were treated with various concentrations of AZ64 or 0.1\% DMSO (control). MTT assay was performed to determine the cell proliferation of the cells after $72 \mathrm{~h}$ of treatment with AZ64. The results indicated that the viability of the cells treated with AZ64 was reduced in all the cell lines compared with the control cells and that the inhibition was enhanced with the increased concentration of AZ64 (Fig. 1A and B). The IC50 values (the drug concentration inhibiting the growth of cell lines by $50 \%$ ) were $2.22,1.32,2.11,4.75,5.94$ and $5.95 \mu \mathrm{M}$ in the A549, HCC827, H1944, H460, H1299 and Calu-1 cell lines, respectively, which indicated that the adenocarcinoma cell lines were more sensitive to AZ64 than the large cell carcinoma cell lines and the squamous carcinoma cell line. Furthermore, the time-response effect of AZ64 on the A549 cells was observed. The cells were treated with AZ64 for $72 \mathrm{~h}$ and the cell index was measured every $30 \mathrm{~min}$ by RT-CES. It was found that the reduction in cell viability was increased with the increased treatment time (Fig. 1C and D). Taken together, these results suggest that AZ64 exerts a potent anti-proliferative effect on NSCLC cells in a dose- and time-dependent manner.

AZ64 inhibits anchorage-independent growth of A549 cells. To further investigate the antitumor effects of AZ64, a soft agar colony formation assay was performed. A549 cells were incubated in soft agar at a low density and treated with either $2.5 \mu \mathrm{M}$ AZ64 or DMSO alone for two weeks. The results revealed that the colonies formed in the cells treated with AZ64 were significantly reduced compared with the untreated cells (Fig. 2A). The colonies of $>100 \mu \mathrm{m}$ were counted in five fixed fields in each well under a light microscope at $\mathrm{x} 4$ magnification. The colony numbers per five fields in the AZ64-treated A549 cells were $29.67 \pm 5.24$ versus $76.33 \pm 4.41$ in the control cells (Student's t-test, $\mathrm{P}<0.01$ ) (Fig. 2B). This suggests that AZ64 has the potential to inhibit the anchorage-independent growth of A549 cells.

AZ64 suppresses invasion activity of A549 cells. To explore the anti- metastatic effect of AZ64 on NSCLC cells, the ability of AZ64 to inhibit A549 cell invasion was examined by BD Matrigel invasion assay. As shown in the Fig. 2C, the number of cells passing through the chamber membrane was significantly reduced in the AZ64-treated group compared with the untreated group. Quantified in a randomly chosen microscopic field at x10 magnification, the number of invasive cells per field was $324.33 \pm 57.50$ in the AZ64-treated group, whereas $1,253 \pm 90.04$ in the untreated group. There was a 


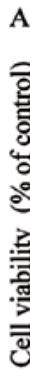

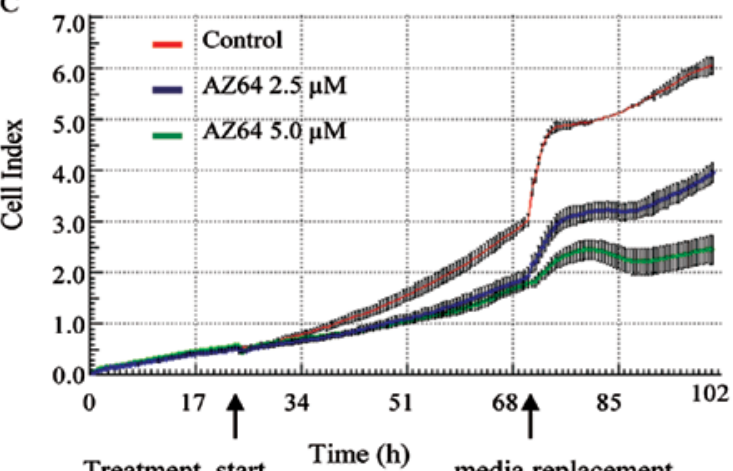

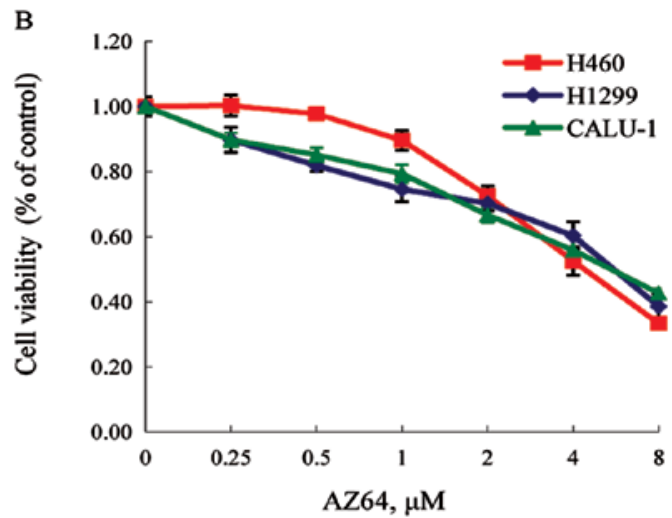

D

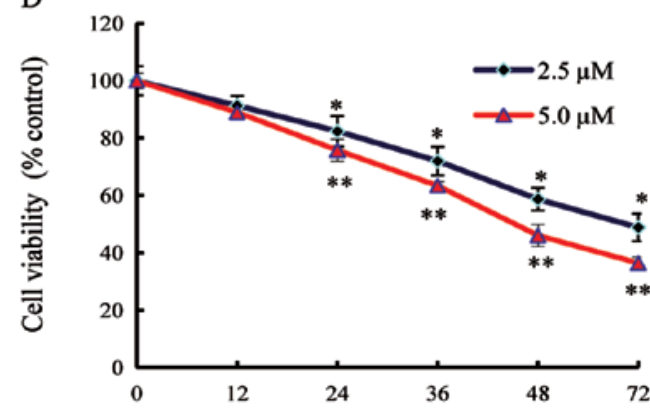

Time after AZ64 treatment (h)

Figure 1. AZ64 inhibited NSCLC cell proliferation in a dose- and time-dependent manner. (A) Three adenocarcinoma cell lines (A549, HCC827 and H1944), (B) Two large cell lung cancer cell lines (H460 and H1299), and one squamous cancer cell line (Calu-1). All six cell lines were treated with AZ64 at various concentrations of $0,0.25,0.5,1.0,2.0,4.0$ and $8.0 \mu \mathrm{M}$ for $72 \mathrm{~h}$. The cell viability was measured by the MTT assay. The data represent the means \pm SD of triplicate experiments. One representative derived from three independent experiments is shown. (C) A549 cells were treated with 2.5 and $5.0 \mu \mathrm{M}$ of AZ64 and $0.1 \%$ DMSO as the control for $72 \mathrm{~h}$. The real-time cell proliferation was measured by the RT-CES system. The shadow area represents SD. (D) The cell viability at time-points of $12,24,36,48$, and $72 \mathrm{~h}$ of treatment was quantified using the RT-CES system. The data are presented as the means \pm SD of triplicate experiments. One representative of three independent experiments is shown. ${ }^{*} \mathrm{P}<0.05 ;{ }^{* *} \mathrm{P}<0.01$, compared with the previous time-point value, based on a paired t-test.
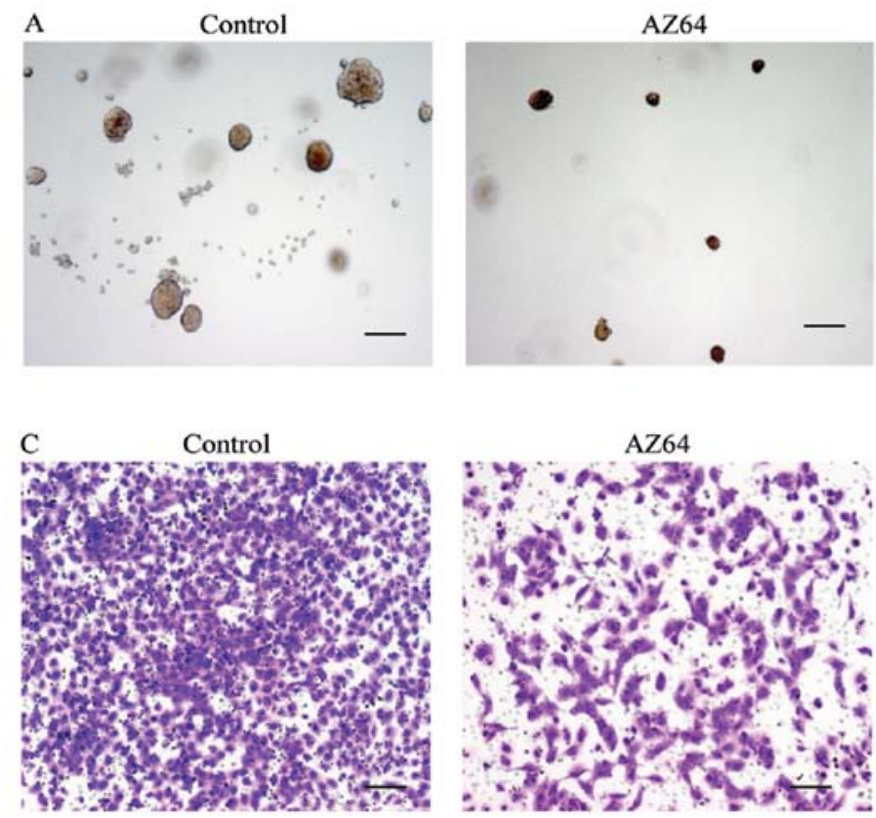
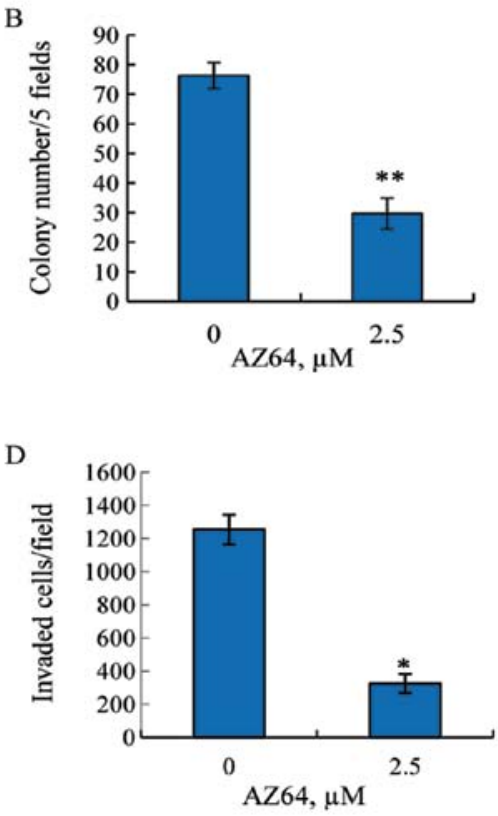

Figure 2. AZ64 reduced the anchorage-independent colony formation and the invasive potential of A549 cells. (A) Single-cell suspension was seeded in soft agar with either $2.5 \mu \mathrm{M}$ AZ64 or $0.025 \%$ DMSO and incubated at $37^{\circ} \mathrm{C}, 5 \% \mathrm{CO}_{2}$ for 2 weeks, and then was observed and photographed under a light microscope. One representative of three independent experiments is shown. Scale bar, $200 \mu \mathrm{m}$. (B) The colonies of $>100 \mu \mathrm{m}$ were counted in five fixed fields of a microscope at $x 4$ magnification for each well. The colony numbers are shown as the means \pm SD from triplicate experiments, derived from one representative of three independent experiments. ${ }^{* *} \mathrm{P}<0.01$, based on the Student's t-test. (C) A549 cells were treated with $2.5 \mu$ M AZ64 or 0.025\% DMSO in BD BioCoat Matrigel invasion chambers for $20 \mathrm{~h}$. The invaded cells on the lower surface of the chamber membranes were stained with crystal violet. One representative of three independent experiments is shown. Scale bar, $100 \mu \mathrm{m}$. (D) The invaded cells were counted in randomly chosen fields under a light microscope at x10 magnification. The data represent the means $\pm \mathrm{SD}$ from three independent experiments. " $\mathrm{P}<0.01$, based on the Student's t-test. 
A
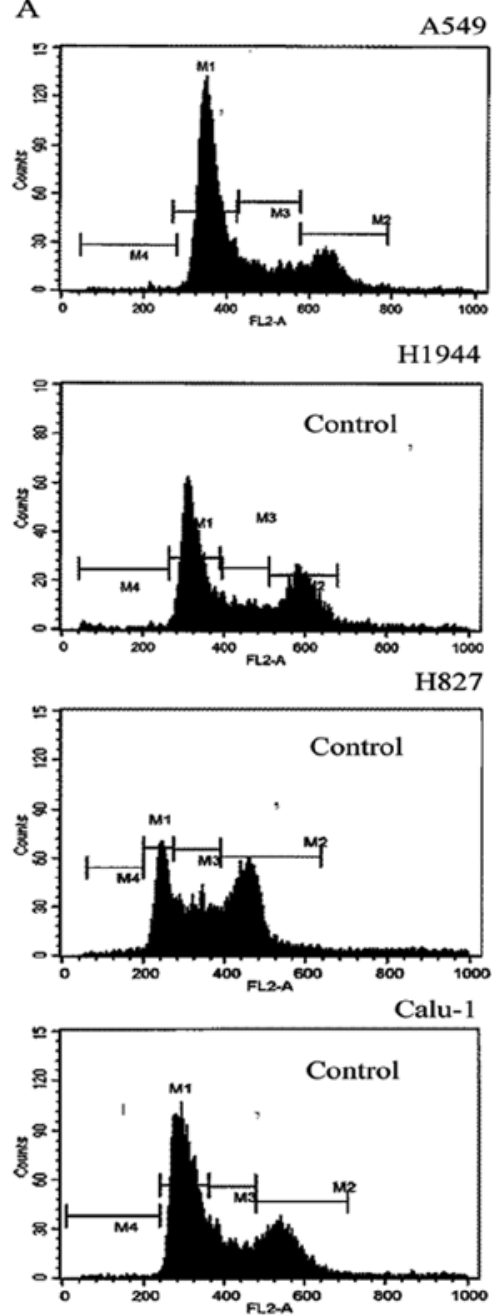
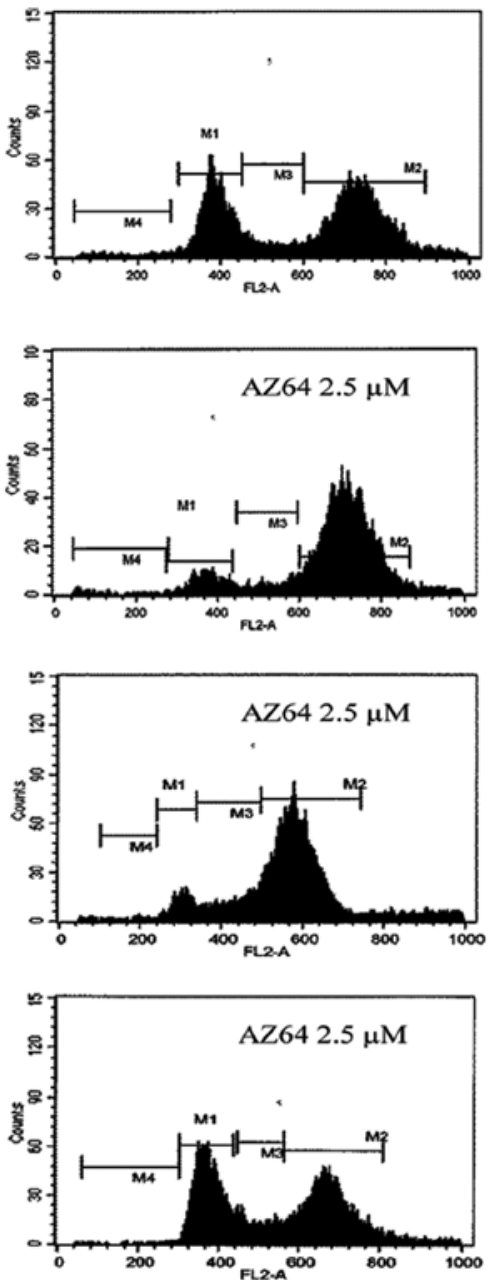

B
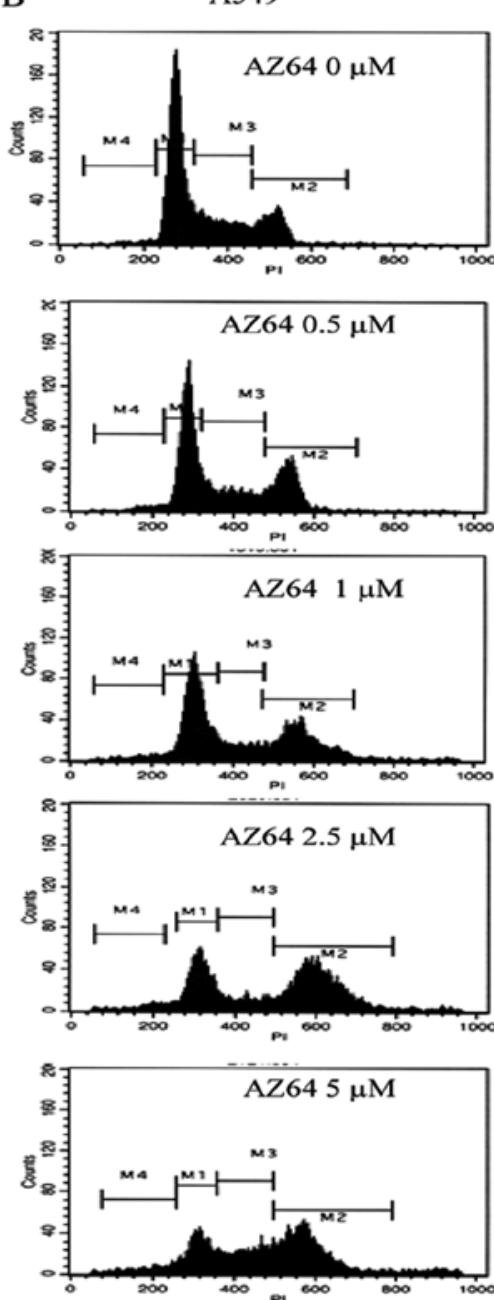

Figure 3. Effects of AZ64 on the cell cycle distribution of NSCLC cells. (A) After $24 \mathrm{~h}$ of exposure to $2.5 \mu \mathrm{M}$ AZ64 or $0.025 \%$ DMSO, the cell cycles of A549, H827, H1944 and Calu-1 cell lines were assayed by flow cytometry. (B) The A549 cells were treated with different concentrations of AZ64 and the cell cycles were measured by flow cytometry. The data shown are representative of at least two separate experiments.

significant difference between these two groups (Student's t-test, $\mathrm{P}<0.01)$ (Fig. 2D). This suggests that AZ64 decreases the invasive capability of A549 cells.

AZ64 induces G2/M arrest of NSCLC Cells. To identify the influence of AZ64 on the cell cycle progress of NSCLC cell lines, the cell cycles were analyzed by FCM. The results showed that the G2/M population in the A549, HCC827, H1944 and Calu-1 cells significantly increased and that the G0/G1 population decreased following treatment with $2.5 \mu \mathrm{M}$ of AZ64 for $24 \mathrm{~h}$, compared with control (Fig. 3A and Table I). To confirm these results, the analysis of the cell cycle in the A549 cells was repeated three times. The population of cells in the $\mathrm{G} 2 / \mathrm{M}$ was $51.41 \pm 3.32 \%$ in the AZ64-treated group versus $17.81 \pm 0.81 \%$ in the control group (Student's t-test, $\mathrm{P}<0.001)$. In the dose-response observation, it was found that the population of A549 cells arrested in the G2/M phase after treatment with AZ64 increased with the increasing concentration of AZ64 (Fig. 3B and Table II). Taken together, these results demonstrate that AZ64 induces the G2/M arrest of NSCLC cells in a dose-dependent manner.
Effect of AZ64 on chromosomes and microtubules in A549 cells. Following the induction of $\mathrm{G} 2 / \mathrm{M}$ phase arrest in the NSCLC cells after AZ64 treatment, we investigated the impact of AZ64 on chromosomes and microtububles, which play an important role in mitosis. The images from the DAPI staining of A549 cells showed that the nuclei size of tbe AZ64-treated A549 cells was enlarged compared with the untreated cells. However, there were no increased proportions of mitotic nuclei characterized as chromosomal condensation, chromosomal alignment and chromosomal segregation in the AZ64-treated cells compared with the control cells. No significant mitotic catastrophe, including multi-nucleation, micronuclei and chromosome bridges was found in the AZ64-treated cells compared with those treated with paclitaxel and the control cells. The proportion of mitotic cells was $2.7 \pm 1.09 \%$ in the AZ64-treated cells versus $3.29 \pm 1.05 \%$ in the DMSO-treated cells. There was no significant difference between the two groups (Student's t-test, $\mathrm{P}=0.398$ ) (Fig. 4A). This suggests that AZ64 led to the arrest of the A549 cells in the G2 phase. Therefore, AZ64 blocks the transition of the A549 cells from the $\mathrm{G} 2$ to the $\mathrm{M}$ phase. 

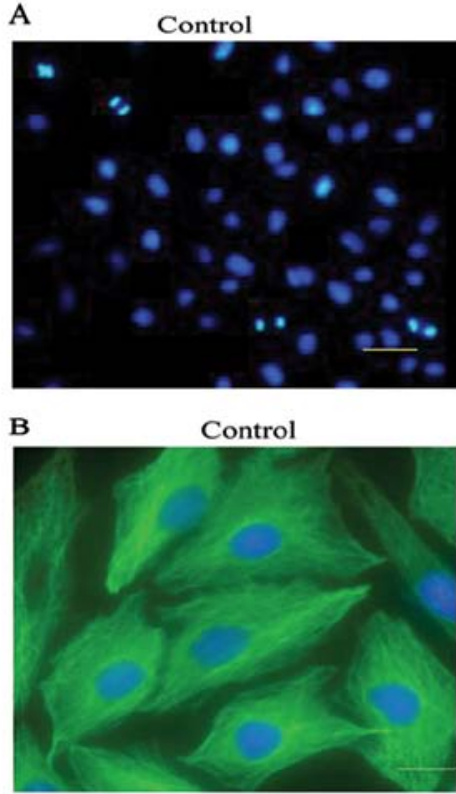
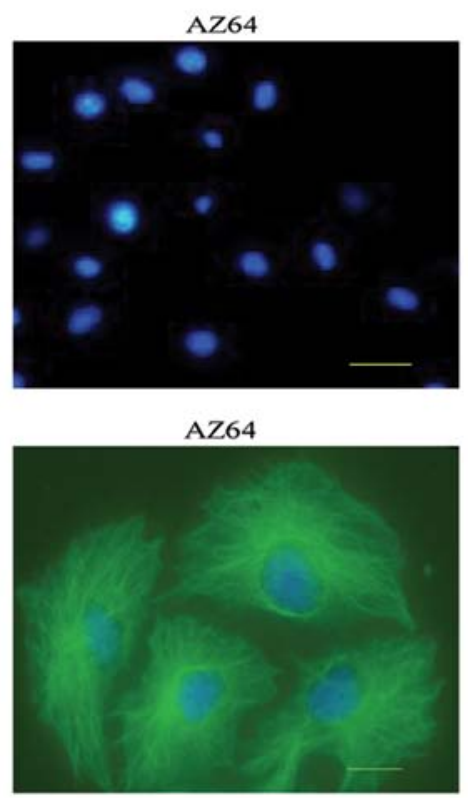
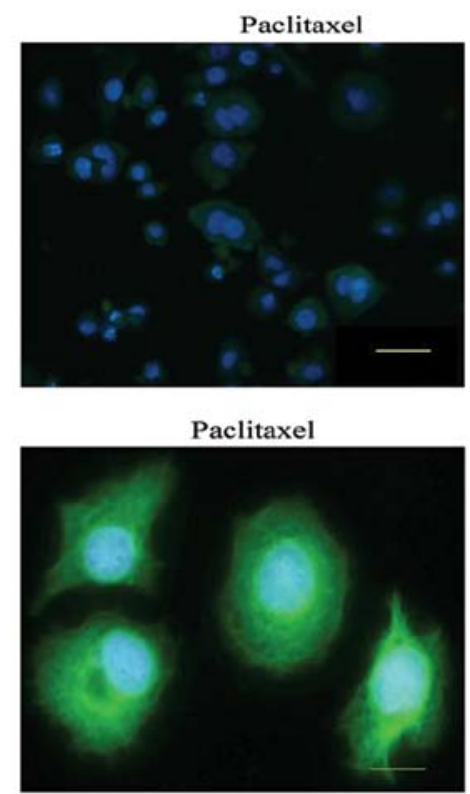

Figure 4. The effects of AZ64 on microtubules and chromosomes in A549 cells. A549 cells were treated with $0.025 \%$ DMSO, $2.5 \mu \mathrm{M}$ AZ64 or $0.0625 \mu \mathrm{g} / \mathrm{ml}$ (73 nM) of paclitaxel for $24 \mathrm{~h}$. (A) Chromosomes were stained with DAPI. (B) The microtubules were stained with $\beta$-tubulin antibody followed by incubation with FITC-conjugated goat anti-mouse IgG. The images were visualized under a fluorescence microscope. The representative from three independent experiments is shown. Scale bar, $50 \mu \mathrm{m}$ in (A) and $20 \mu \mathrm{m}$ in (B).

Table I. Effect of AZ64 on the cell cycle distribution of NSCLC cells.

\begin{tabular}{llrrc}
\hline Cell lines & Treatment & G0/G1 (\%) & S (\%) & G2/M (\%) \\
\hline A549 & Control & 64.44 & 16.21 & 17.54 \\
& AZ64 & 33.17 & 8.48 & 54.55 \\
HCC827 & Control & 24.25 & 27.13 & 43.04 \\
& AZ64 & 7.22 & 14.24 & 70.01 \\
H1944 & Control & 50.71 & 13.94 & 30.59 \\
& AZ64 & 8.79 & 6.30 & 81.40 \\
Calu-1 & Control & 55.90 & 18.75 & 24.14 \\
& AZ64 & 38.78 & 11.78 & 44.66 \\
\hline
\end{tabular}

After $24 \mathrm{~h}$ of exposure to $2.5 \mu \mathrm{M}$ of AZ64 or $0.025 \%$ DMSO, the cell cycles of A549, HCC827, H1944 and Calu-1 cells were assayed by flow cytometry with PI staining.

Moreover, we performed immunofluorescence staining of microtubules with anti- $\beta$-tubulin monoclonal antibody followed by FITC-conjugated goat anti-mouse IgG. No aberrant microtubule depolymerization or disruption was found in the AZ64-treated A549 cells compared with the untreated cells; however, aberrant microtubule depolymerization was evident in the cells treated with anti-microtubule drug. The paclitaxel-treated cells exhibited aberrant microtubule depolymerization or disruption (Fig. 4B). Therefore, we concluded that the G2/M arrest of A549 cell induced by AZ64 may be a result of the reduced chromosomal activity, and not from aberrant microtubule depolymerization.
Table II. Effect of the different concentrations of AZ64 on cell cycle distribution of A549 cells.

\begin{tabular}{lccc}
\hline AZ64 $(\mu \mathrm{M})$ & G0/G1 (\%) & $\mathrm{S}(\%)$ & $\mathrm{G} 2 / \mathrm{M}(\%)$ \\
\hline 0 & 58.37 & 22.76 & 17.24 \\
0.5 & 55.80 & 22.23 & 20.46 \\
1.0 & 49.16 & 13.04 & 33.19 \\
2.5 & 28.56 & 12.42 & 52.08 \\
5.0 & 22.21 & 24.26 & 45.41 \\
\hline
\end{tabular}

After $24 \mathrm{~h}$ of exposure to $0.025 \%$ DMSO or indicated concentrations of AZ64, the cell cycles of A549 cells were assayed by flow cytometry with PI staining.

Impact of AZ64 on proteins related to G2/M transition in A549 cells. Considering the important role of AZ64 in G2/M transition, the impact of AZ64 on the expression of the proteins related to the $\mathrm{G} 2 / \mathrm{M}$ checkpoint was examined. Following treatment with $2.5 \mu \mathrm{M}$ of AZ64 for $0,2,4,6,8,12,16,24$ and $36 \mathrm{~h}$, the expression of Aurora-A, Plk1, Cdc25C, Cdc2, phospho-Cdc2 (Tyr15) and cyclin B was measured by western blot analysis in the A549 cells. The results showed that the expression of phospho-Cdc2 (Tyr15) was increased and that of Cdc25C was reduced in the AZ64-treated A549 cells after $6 \mathrm{~h}$ of exposure compared with the untreated cells. The Aurora-A, Plk1, Cdc2 and cyclin B expression levels were not altered following treatment with AZ64 (Fig. 5A). This implies that AZ64 inhibits the dephosphorylation of phospho-Cdc2 (Tyr15) by decreasing the expression of $\mathrm{Cdc} 25 \mathrm{C}$, which contributes to $\mathrm{G} 2 / \mathrm{M}$ arrest. However, the levels of cyclin B were enhanced after $24 \mathrm{~h}$ of 
A

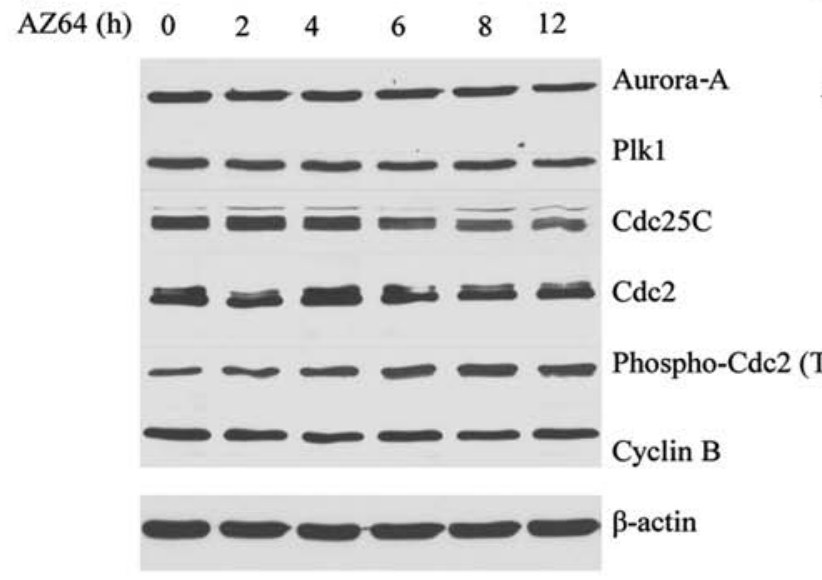

B

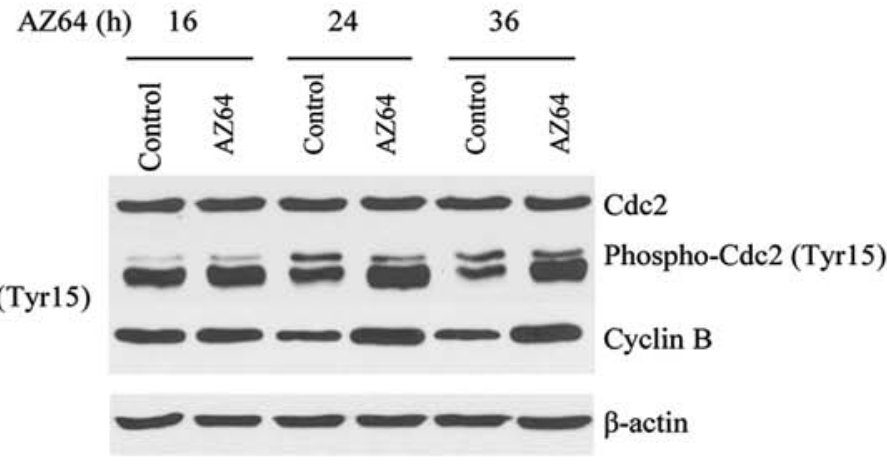

C Control AZ64
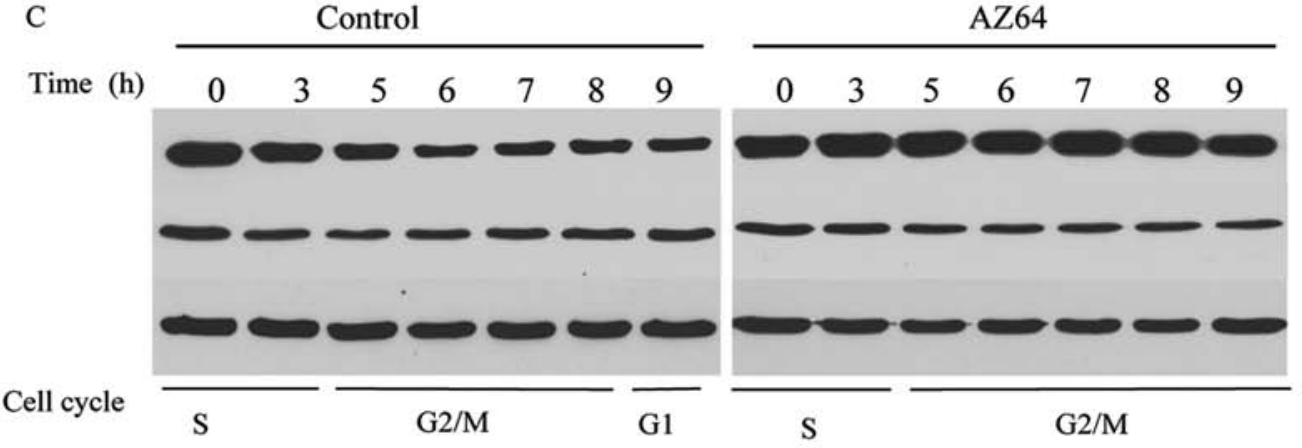

Phospho-Cdc2 (Tyr15)

$\mathrm{Cdc} 2$

$\beta$-actin

Figure 5. The AZ64-induced alterations in the G2/M checkpoint protein levels. The A549 cells were treated with $2.5 \mu \mathrm{M}$ AZ64 for the indicated times. The expression of Aurora-A, Plk, Cdc25C, Cdc2, phospho-Cdc2 (Tyr15) and cyclin B was determined by western blot analysis. The expression proteins in the early phase (0-14 h) (A) and late phase (16-36 h) following treatment (B) were assessed by separate experiments. (C) A549 cells were synchronized by thymidine and were then treated with $2.5 \mu \mathrm{M}$ AZ64 or $0.025 \%$ DMSO at the time of thymidine release. The expression of phospho-cdc2 (Tyr15) and Cdc2 was assessed by western blot analysis at the treatment times of $0,3,5,6,7,8$ and $9 \mathrm{~h}$. The experiment was repeated two times.

treatment with AZ64 (Fig. 5B). A possible explanation is that the $\mathrm{G} 2 / \mathrm{M}$ arrest may abrogate the degradation of cyclin $\mathrm{B}$.

To further elucidate the effect of the alteration of phosphoCdc2 (Tyr15) levels on the cell cycle, we synchronized the A549 cells with thymidine treatment and treated them with $2.5 \mu \mathrm{M}$ of AZ64 or $0.025 \%$ DMSO alone after thymidine release. The cells were harvested at $0,3,5,6,7,8$ and $9 \mathrm{~h}$ after AZ64 treatment and the levels of phospho-Cdc2 (Tyr15) and Cdc2 were examined by western blot analysis. The cell cycle activities were measured by FCM. The results demonstrated that the phospho-Cdc2 (Tyr15) level in the control cells decreased at the time of the G2/M transition, although the phospho-Cdc2 (Tyr15) level in the AZ64-treated A549 cells dramatically increased at the time of the $\mathrm{G} 2 / \mathrm{M}$ transition, while there was no significant change in total Cdc2 expression (Fig. 5C). This demonstrates that AZ64 inhibits the dephosphorylation of phospho-Cdc2 (Tyr15) at the time of the G2/M transition, which results in $\mathrm{G} 2 / \mathrm{M}$ arrest.

To verify the effect of AZ64 on the dephosphorylation of phospho-Cdc2 (Tyr15), the ICC staining of phospho-Cdc2 (Tyr15) was performed on the A549 cells. As shown in Fig. 6, high levels of phospho-Cdc2 (Tyr15) accumulated in the nuclei of the AZ64-treated A549 cells compared with the DMSOtreated control cells. The H-score of phospho-Cdc2 (Tyr15) was $267 \pm 15$ in the AZ64-treated cells versus $157 \pm 12$ in the untreated cells (Student's t-test, $\mathrm{P}<0.01$ ) (Fig. 6A and B). These results further demonstrate that AZ64 inhibits the dephosphorylation of phospho-Cdc2 (Tyr15), which is consistent with the findings from western blot analysis.

AZ64 inhibits tumor growth in the A549 xenograft model. To determine the antitumor effect of AZ64 in vivo, A549 cells were xenografted into nude mice. When the tumors were measurable (approximately $60-100 \mathrm{~mm}^{3}$ ), AZ64 or vehicle was administrated by gavage, and the tumor size and mouse weight were measured for a total of 36 days. It was found that the average tumor volume of the A549 xenografted nude mice was reduced in the AZ64-treated group compared to the control group starting from day 20 (Student's t-test, $\mathrm{P}<0.05$ from day 20 to $24 ; \mathrm{P}<0.01$ from day 28 to 36 ; Fig. $7 \mathrm{~A})$. To evaluate the toxicity of AZ64, the body weights of the nude mice were measured. There are no difference in body weight between the AZ64-treated group and the control group after treatment (Student's t-test, P>0.05; Fig. 7B).

\section{Discussion}

In this study, we found that AZ64 inhibits the proliferation of all major subtypes of NSCLC cells, including adenocarcinoma, large cell carcinoma and squamous carcinoma. The IC50 of 
A

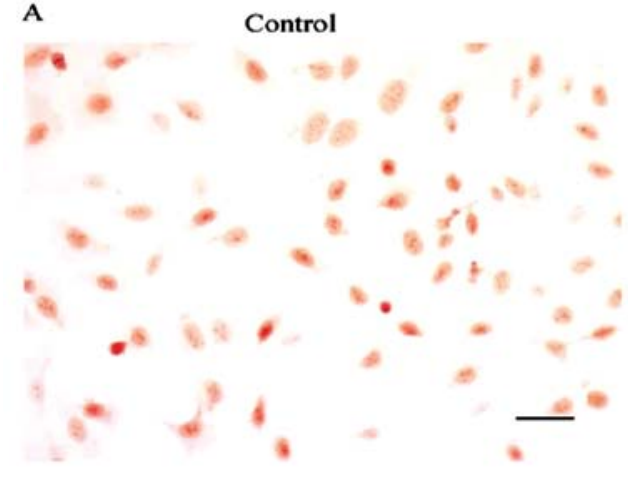

B

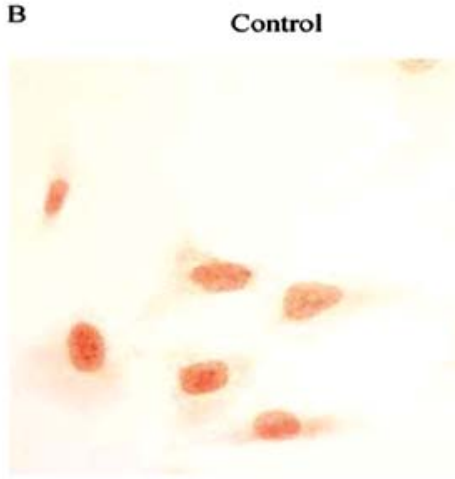

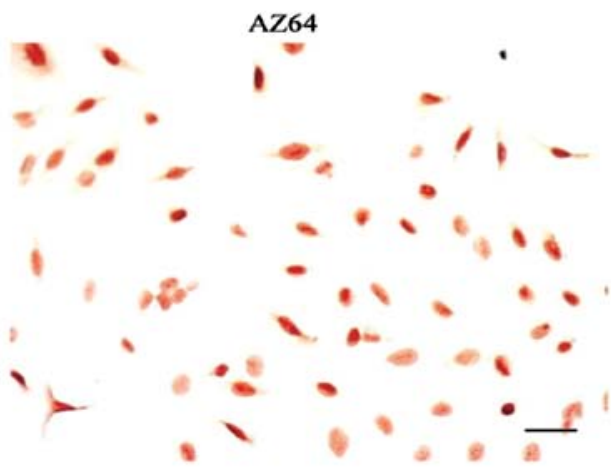

AZ64

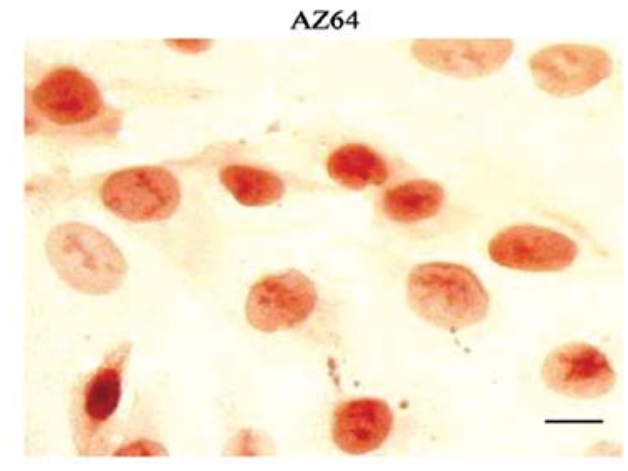

Figure 6. The expression of phospho-Cdc2 (Tyr15) in the A549 cells was detected by immunocytochemistry staining. After treatment with $2.5 \mu \mathrm{M}$ AZ64 or $0.025 \%$ DMSO for $6 \mathrm{~h}$, the cells were stained with ABC Reagent and the staining was visualized under a light microscope. The extent of phospho-cdc2 (Tyr15) staining was calculated using the $\mathrm{H}$-score semi-quantitative method The representatives of triplicates are shown. Scale bar, $50 \mu \mathrm{M}$ (upper panel) and $20 \mu \mathrm{M}$ (lower panel).

A

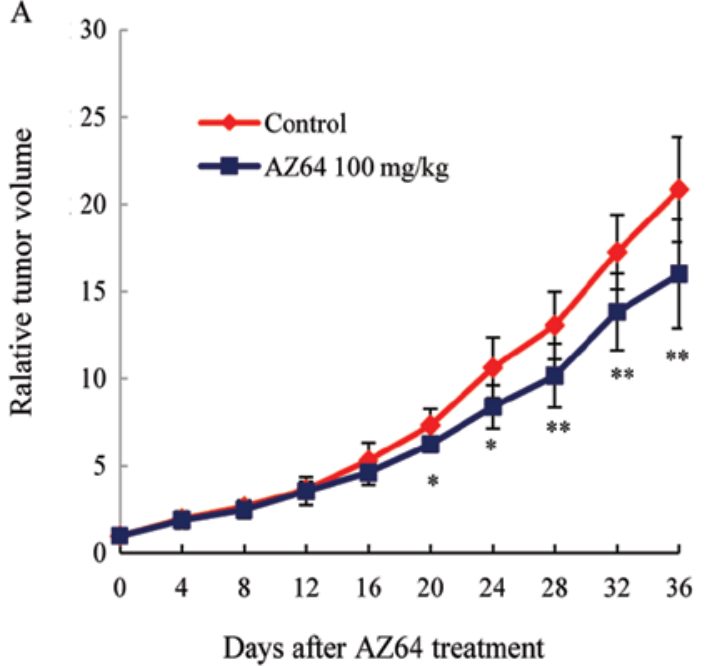

B

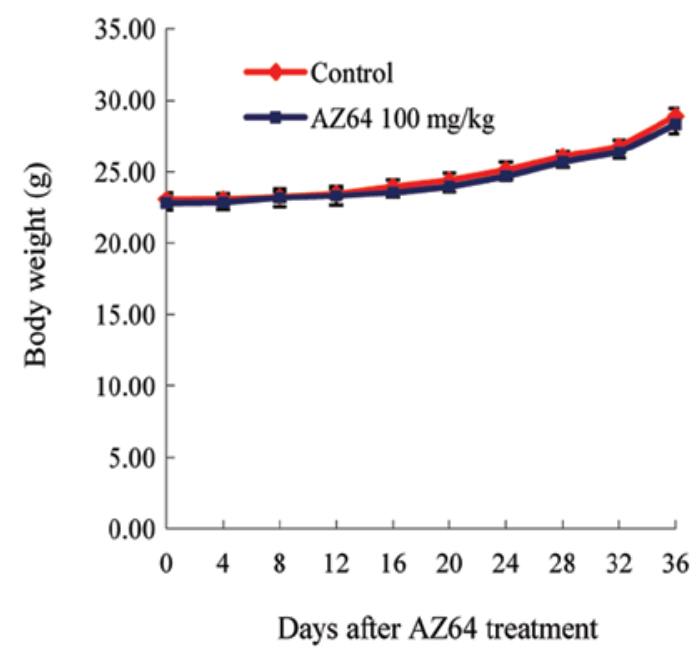

Figure 7. AZ64 inhibits the growth of human tumor xenografts. A549 cells were implanted into the dorsal site of the nude mice by s.c. injection. When tumors reached $60-110 \mathrm{~mm}^{3}$ in volume, the mice were randomly divided into the AZ64-treated group and the control group. AZ64 (100 mg/kg/day) or the vehicle were administered via gavage. (A) The relative volumes of tumors are shown. (B) Body weights of the mice were measured every 4 days for 36 days. ${ }^{*}<0.05$, ${ }^{* *} \mathrm{P}<0.01$, based on the Student's t-test.

these cell lines ranged from 1.32 to $5.95 \mu \mathrm{M}$, which is similar to that obtained in other reports $(7,8)$. Based on the IC50 values, it was revealed that the adenocarcinoma cell lines were more sensitive to AZ64 than the large cell carcinoma cell lines and the squamous carcinoma cell line. It was also shown that
AZ64 exerts an anti-proliferative effect on the NSCLC cells in a dose- and time-dependent manner. Moreover, the soft agar colony formation assay demonstrated that AZ64 dramatically inhibited the anchorage-independent growth of A549 cells and Matrigel invasion assay showed that AZ64 significantly inhib- 
ited cell invasion. Collectively, these data suggest that AZ64 has the potential to inhibit the tumor growth and metastasis of NSCLC cells in vitro.

Our in vivo experiments showed that the tumor growth in the AZ64-treated mice was slower than the control group. Of note, there was no significant weight loss in the AZ64-treated mice compared with the control group. These results imply that AZ64 has the ability to inhibit tumor growth in vivo and is well tolerated by mice.

The biological mechanisms of antitumor drugs include the inhibition of proliferation, growth arrest in the cell cycle, enhanced apoptosis and the modulation of signal transduction pathways. Trks are a family of receptor tyrosine kinases (RTKs), including three members, TrkA, TrkB and TrkC, which bind with its ligand neurotrophins (NTs) to mediate the trophic effects of the nerve (9). They are expressed in a variety of human cancers, such as neuroblastomas, glioblastomas, prostatic adenocarcinomas and papillary thyroid carcinomas (10). AZ64 as originally developed as a Trk inhibitor, acting as a kinase inhibitor by competing with the binding of ATP to the catalytic domain. It acts as a Trk inhibitor at low concentrations (single nanomole) but acts as a multiple kinase inhibitor at high concentrations (11). It has been reported to inhibit the growth of neuroblastoma cells at a nanomole range of IC50 (12), and to inhibit the growth of lung cancer cells at the micromole range (IC50) $(7,8)$. At these concentrations, the mechanism of action of AZ64 should to be further investigated. It is possible that AZ64 targets multiple kinases.

Our results from FCM analysis indicated that AZ64 dramatically increased the number of A549, HCC827, H1944 and Calu- 1 cells in the G2/M phase. During the dose-dependent observation, we found that the inhibitory effect of AZ64 on the G2/M phase occurred in dose-dependent manner. These results strongly suggest that AZ64 induces G2/M arrest in NSCLC cells. Moreover, we examined the morphological alteration of the A549 cells after treatment with AZ64, focusing on chromosomes and microtubules. We observed that the cell and nucleus were enlarged after AZ64 treatment. However, although A549 cells were arrested in the G2/M phase by AZ64, there was no increase in the mitotic index in the AZ64-treated A549 cells compared with the untreated cells. This illustrates that A549 cells are mostly arrested in the G2 phase and do not reach the $M$ phase. Therefore, it can be concluded the transition of the A549 cells from the G2 to the $M$ phase is blocked. In addition, no obvious mitotic catastrophe, such as multi-nucleation, micronuclei and chromosome bridges was found and no aberrant microtubule depolymerization or polymerization were observed in the AZ64-treated cells compared with the untreated cells. Different results were observed in the paclitaxel-treated cells, in which aberrant microtubule depolymerization and mitotic catastrophe were evident. This indicates that AZ64 blocks the cells in the G2/M phase not via microtubule inhibition but via other potential mechanisms.

The cell cycle progression at the $\mathrm{G} 2 / \mathrm{M}$ phase was triggered by the checkpoint known as $\mathrm{Cdc} 2 /$ cyclin $\mathrm{B}$. The activation of $\mathrm{Cdc} 2 /$ cyclin B initiates the entry of the cells from the G2 to the $\mathrm{M}$ phase through the phosphorylation of proteins that correlate with chromosomal condensation, nuclear envelope breakdown and spindle assembly (13). In addition to binding with cyclin $\mathrm{B}$, the activation of $\mathrm{Cdc} 2$ is regulated by a series of phosphorylation and dephosphorylation events. The dephosphorylation of the Thr14 and Tyr15 amino acids (14) and the phosphorylation of the Thr161 amino acid promote the activation of Cdc2. As the dephosphorylation of the Thr14 and Tyr15 amino acids plays an important role in the G2/M transition, to elucidate the molecular mechanism of the antitumor effect of AZ64, we investigated the influence of AZ64 on the regulatory proteins involved in $\mathrm{G} 2 / \mathrm{M}$ transition in the A549 cells. It was found that phospho-Cdc2 (Tyr15) levels significantly increased in the AZ64-treated A549 cells compared to the untreated cells, while no significant difference was observed in the $\mathrm{Cdc} 2$ and cyclin B levels between the two groups. For further verification, we synchronized the A549 cells with thymidine and treated them with AZ64. It was also found that the phospho-Cdc2 (Tyr15) levels dramatically increased in the AZ64-treated A549 cells, while the phospho-Cdc2 (Tyr15) levels were decreased in the untreated cells at the G2/M transition. Moreover, ICC staining was performed and the results revealed that phospho-Cdc2 (Tyr15) levels increased in the nuclei of the AZ64-treated cells compared with the control group. Collectively, these results suggest that AZ64 blocks the G2/M transition by inhibiting the dephosphorylation of phospho-Cdc2 (Tyr15).

The dephosphorylation of phospho-Cdc2 (Tyr14 and Tyr15) is facilitated by $\mathrm{Cdc} 25 \mathrm{C}$ phosphatase and the phosphorylation of Cdc2 on Tyr14 and Tyr15 is catalyzed by a protein kinase known as Wee1 (15). At the end of the G2 phase, the abrupt dephosphorylation of phospho-Cdc2 (Tyr14 and Tyr15) by Cdc25C triggers the activation of Cdc2/cyclin B and promotes the cell cycle progression to the $\mathrm{M}$ phase. $\mathrm{Cdc} 25 \mathrm{C}$ is inactivated by the phosphorylation of Ser216 by Chk1 and Chk2 during the interphase, which binds 14-3-3 proteins and maintains its cytoplasmic location (16). During the G2/M transition, Cdc25C is activated by the phosphorylation of Ser198 and enters the nucleus to activate $\mathrm{Cdc} 2 /$ cyclin B by dephosphorylating phospho-Cdc2 (Tyr14 and Tyr15). The phosphorylation of Cdc25C on Ser198 and its nuclear translocation are facilitated by Plk1 (17) which is a serine/threonine kinase and activated by its upstream protein kinase, Aurora-A (18).

We further determined the levels of Aurora-A, Plk1 and Cdc25C in the A549 cells after AZ64 treatment. The results showed that the Cdc25C protein level was downregulated; however, the Aurora-A and Plk1 levels were not affected. This implied that the reduction in the dephosphorylation of phospho-Cdc2 (Tyr15) in the AZ64-treated cells resulted from the downregulation of Cdc25C by AZ64. However, the phosphorylated forms of Aurora-A and Plk1 need to be investigated for the evaluation of the effect of AZ64 on the Aurora-Plk pathway.

In general, a cell with a suppressed cyclin B1/Cdc2 activity tends to be arrested in the G2 phase, whereas a cell with an elevated cyclin B1/Cdc2 activity enters mitosis. However, a number of reports have presented conflicting results, demonstrating that cyclin B levels are increased in the cells arrested in G2/M. Choi et al (19) showed that cyclin B upregulation and plays an important role in the prometaphase arrest in nocodazole-treated cells. Wang et al (20) reported elevated cyclin B, Cdc2 and Cdc25C levels in cells in G2/M arrest by the knockdown of Plk1. In this study, the alteration in cyclin B levels was biphasic, in that no change was observed in the early 
phase (0-24 h), while an increase was observed in the later phase (24-36 h) after AZ64 treatment. Based on the knowledge that regulatory proteins involved in the G2/M transition accumulate to initiate entry into the $\mathrm{M}$ phase and are degraded in the metaphase-anaphase transition to allow mitotic exit $(21,22)$, it is speculated that the reduced $\mathrm{Cdc} 2 /$ cyclin $\mathrm{B}$ complex activity cannot activate the anaphase promoting complex (APC), and therefore, this abrogates the degradation of cyclin $\mathrm{B}$ and thereby enhances the levels cyclin B. However, further studies are required in order to confirm this hypothesis.

The targeting of the G2/M transition in the cell cycle is an important strategy of cancer therapy. The only drugs targeting the $\mathrm{G} 2 / \mathrm{M}$ phase currently used in clinical medicine are microtubule inhibitors, such as vinca alkaloids (vincristine, vinblastine and vinorelbine), inhibitors of microtubule polymerization and taxanes (paclitaxel and docetaxel), both leading to mitotic catastrophe and cell death (23). However, the microtubule inhibitors destroy microtubules not only in the proliferated cells but also in the non-proliferated cells, which induces a systemic cytotoxic effect. Therefore, the development of new drugs targeting the $\mathrm{G} 2 / \mathrm{M}$ phase may provide a potential novel strategy for anticancer therapy.

A number of compounds have been reported to have the potential to inhibit NSCLC cell growth by downregulatig the expression of Cdc2 or cyclin B $(24,25)$. However, to date, no antitumor agent has been reported to suppress NSCLC cell growth by reducing the dephosphorylation of phospho-Cdc2 (Tyr15). Lee et al reported that 2-methoxyestradiol induced G2/M cell-cycle arrest via the accumulation of phospho-Cdc2 (Tyr15) in a nasopharyngeal carcinoma cell line (26). Their findings are similar to the ones from our study. However, Zhang et al demonstrated that the reduced phospho-Cdc2 (Tyr15) levels by 8-chloro-adenosine resulted in mitotic catastrophe in A549 cells (27), which is in conflict with our results. We found that AZ64 inhibited the dephosphorylation of phospho-Cdc2 (Tyr15) via the reduction of $\mathrm{Cdc} 25 \mathrm{C}$ expression and therefore enhanced the phospho-Cdc2 (Tyr15) level at the G2/M transition in the A549 cells. The IC50 of AZ64 was lower than the other Cdc2/cyclin B inhibitors $(24,28)$. These results indicate that AZ64 effectively blocks the cells in the G2/M phase via the inhibition of $\mathrm{Cdc} 2 /$ cyclin B activity at the G2/M checkpoint.

In conclusion, in this study, we investigated the antitumor effect of AZ64 on NSCLC cells, as well as its mechanism of action. Our results demonstrate that AZ64 inhibits the growth of NSCLC cells in vitro and in vivo and decreases the invasive ability of the cells. AZ64 treatment leads to cells arresting in the $\mathrm{G} 2$ phase and blocks the cell cycle progression. The reduced dephosphorylation of phospho-Cdc2 (Tyr15) at the $\mathrm{G} 2 / \mathrm{M}$ transition may be one of the molecular mechanisms involved.

\section{Acknowledgements}

The agent AZ64 was supplied by AstraZeneca Pharmaceuticals via an MD Anderson - AstraZeneca MTA.

\section{References}

1. Siegel R, Naishadham D and Jemal A: Cancer statistics, 2012 CA Cancer J Clin 62: 10-29, 2012.
2. McErlean A and Ginsberg MS: Epidemiology of lung cancer. Semin Roentgenol 46: 173-177, 2011.

3. Jemal A, Siegel R, Ward E, Murray T, Xu J, Smigal C and Tun MJ: Cancer statistics. CA Cancer J Clin 56: 106-130, 2006.

4. Hsu HF, Huang KH, Lu KJ, Chiou SJ, Yen JH, Chang CC and Houng JY: Typhonium blumei extract inhibits proliferation of human lung adenocarcinoma A549 cells via induction of cell cycle arrest and apoptosis. J Ethnopharmacol 135: 492-500, 2011.

5. Xu X, Zhang Y, Qu D, Jiang T and Li S: Osthole induces G2/M arrest and apoptosis in lung cancer A549 cells by modulating PI3K/Akt pathway. J Exp Clin Cancer Res 30: 33, 2011.

6. Wilkinson RW, Odedra R, Heaton SP, Wedge SR, Keen NJ, Crafter C, Foster JR, Brady MC, Bigley A, Brown E, Byth KF, Barrass NC, Mundt KE, Foote KM, Heron NM, Jung FH, Mortlock AA, Boyle FT and Green S: AZD1152, a selective inhibitor of Aurora B kinase, inhibits human tumor xenograft growth by inducing apoptosis. Clin Cancer Res 13: 3682-3688, 2007.

7. Harada T, Yatabe Y, Takeshita M, Koga T, Yano T, Wang Y and Giaccone G: Role and relevance of TrkB mutations and expression in non-small cell lung cancer. Clin Cancer Res 9: 2638-2645, 2011

8. Yilmaz T, Jiffar T, Garza G, Lin H, Milas Z, Takahashi Y, Hanna E, MacIntyre T, Brown JL, Myers JN, Kupferman ME and Michael E: Theraputic targeting of Trk supresses tumor proliferation and enhances cisplatin activity in HNSCC. Cancer Biol Ther 10 : 644-653, 2010

9. Brodeur GM, Minturn JE, Ho R, Simpson AM, Iyer R, Varela CR, Light JE, Kolla V and Evans AE: Trk receptor expression and inhibition in neuroblastomas. Clin Cancer Res 10: 3244-3250, 2009.

10. Koizumi H, Morita M, Mikami S, Shibayama E and Uchikoshi T: Immunohistochemical analysis of TrkA neurotrophin receptor expression in human non-neuronal carcinomas. Pathol Int 2: 93-101, 1998.

11. Thress K, Macintyre T, Wang H, Whitston D, Liu ZY, Hoffmann E, Wang T, Brown JL, Webster K, Omer C, Zage PE, Zeng $\mathrm{L}$ and Zweidler-McKay PA: Identification and preclinical characterization of AZ-23, a novel, selective, and orally bioavailable inhibitor of the Trk kinase pathway. Mol Cancer Ther 7: 1818-1827, 2009.

12. Iyer R, Varela CR, Minturn JE, Ho R, Simpson AM, Light JE, Evans AE, Zhao H, Thress K, Brown JL and Brodeur GM: AZ64 inhibits TrkB and enhances the efficacy of chemotherapy and local radiation in neuroblastoma xenografts. Cancer Chemother Pharmacol: May 24, 2012 (Epub ahead of print).

13. Castedo M, Perfettini JL, Roumier T and Kroemer G: Cyclindependent kinase-1: linking apoptosis to cell cycle and mitotic catastrophe. Cell Death Differ 9: 1287-1293, 2002.

14. Lindqvist A, Rodríguez-Bravo V and Medema RH: The decision to enter mitosis: feedback and redundancy in the mitotic entry network. J Cell Biol 185: 193-202, 2009.

15. Telles E, Gurjar M, Ganti K, Gupta D and Dalal SN: Filamin A stimulates Cdc25C function and promotes entry into mitosis. Cell Cycle 10: 776-782, 2011.

16. Peng CY, Graves PR, Thoma RS, Wu Z, Shaw AS and Piwnica-Worms H: Mitotic and G2 checkpoint control: regulation of 14-3-3 protein binding by phosphorylation of Cdc25C on serine-216. Science 277: 1501-1505, 1997.

17. Toyoshima-Morimoto F, Taniguchi E and Nishida E: Plk1 promotes nuclear translocation of human Cdc25C during prophase. EMBO Rep 4: 341-348, 2002.

18. Seki A, Coppinger JA, Jang CY, Yates JR and Fang G: Bora and the kinase Aurora A cooperatively activate the kinase Plk1 and control mitotic entry. Science 20: 1655-1658, 2008.

19. Choi HJ, Fukui M and Zhu BT: Role of cyclin B1/Cdc2 up-regulation in the development of mitotic prometaphase arrest in human breast cancer cells treated with nocodazole. PLoS One 6: e24312, 2011.

20. Wang ZX, Xue D, Liu ZL, Lu BB, Bian HB, Pan X and Yin YM: Overexpression of polo-like kinase 1 and its clinical significance in human non-small cell lung cancer. Int J Biochem Cell Biol 44: 200-210, 2012.

21. Lens SM, Voest EE and Medema RH: Shared and separate functions of polo-like kinases and aurora kinases in cancer. Nat Rev Cancer 10: 825-841, 2010.

22. Chang DC, Xu N and Luo KQ: Degradation of cyclin B is required for the onset of anaphase in mammalian cells. J Biol Chem 278: 37865-37873, 2003. 
23. Jorgensen TJ, Tian H, Joseph IB, Menon K and Frost D: Chemosensitization and radiosensitization of human lung and colon cancers by antimitotic agent, ABT-751, in athymic murine xenograft models of subcutaneous tumor growth. Cancer Chemother Pharmacol 59: 725-732, 2007.

24. Hsiao YC, Hsieh YS, Kuo WH, Chiou HL, Yang SF, Chiang WL and Chu SC: The tumor-growth inhibitory activity of flavanone and 2 '-OH flavanone in vitro and in vivo through induction of cell cycle arrest and suppression of cyclins and CDKs. J Biomed Sci 14: 107-119, 2007.

25. Shyu KG, Huang ST, Kuo HS, Cheng WP and Lin YL: Antitumor activity of a novel bis-aziridinylnaphthoquinone (AZ4) mediating cell cycle arrest and apoptosis in non-small cell lung cancer cell line NCI-H4601. Acta Pharmacol Sin 28: 559-566, 2007.
26. Lee YM, Ting CM, Cheng YK, Fan TP, Wong RN, Lung ML and Mak NK: Mechanisms of 2-methoxyestradiol-induced apoptosis and G2/M cell-cycle arrest of nasopharyngeal carcinoma cells. Cancer Lett 268: 295-307, 2008.

27. Zhang HY, Gu YY, Li ZG, Jia YH, Yuan L, Li SY, An GS, $\mathrm{Ni} \mathrm{JH}$ and Jia HT: Exposure of human lung cancer cells to 8-chloro-adenosine induces $\mathrm{G} 2 / \mathrm{M}$ arrest and mitotic catastrophe. Neoplasia 6: 802-812, 2004.

28. Chen YL, Lin SZ, Chang JY, Cheng YL, Tsai NM and Chen SP: In vitro and in vivo studies of a novel potential anticancer agent of isochaihulactone on human lung cancer A549 cells. Biochem Pharmacol 72: 308-319, 2006. 